\title{
Retos para la cooperación al desarrollo en el post-2015
}

\author{
RAFAel DomíngueZ a , ILIANA OLIVIÉ ${ }^{\text {b }}$ \\ a Cátedra de Cooperación Internacional y con Iberoamérica, Universidad de Cantabria, E.T.S. \\ Caminos, Canales y Puertos, Avda. de los Castros s/n, 39005 Santander, España. E- \\ mail: domingur@unican.es \\ ${ }^{b}$ Fundación Real Instituto Elcano, c/ Príncipe de Vergara, 51, 28006 Madrid, España. E- \\ mail: iolivie@rielcano.org
}

\begin{abstract}
RESUMEN
Entre las consecuencias de la emergencia de nuevos poderes regionales a globales está, por una parte, la aparición, consolidación o fortalecimiento de nuevos donantes y, por otra, el cambio del mapa del desarrollo y la pobreza mundiales. Es en este nuevo contexto en el que tiene que configurarse la nueva agenda del desarrollo -la agenda post2015- que vendrá a remplazar los, ya viejos, Objetivos de Desarrollo del Milenio. Este artículo expone el estado actual de la gestación de esta agenda post-ODM a un año de su aprobación y teniendo en cuenta que el debate sobre sus contenidos y gobierno aún está abierto. Concretamente, se analiza la creciente importancia de las desigualdades como elemento de la agenda de desarrollo global y se pormenorizan los detalles sobre el eventual gobierno del futuro sistema de cooperación internacional por el que, a fecha de hoy, pugnan las Naciones Unidas y la OCDE.
\end{abstract}

Palabras clave: Desarrollo, cooperación, pobreza, desigualdad, gobernanza, emergentes.

\section{Challenges for Development Cooperation in the Post-2015}

\begin{abstract}
Among the consequences of the emergence of new regional powers to global is, first, the emergence, consolidation or strengthening of new donors and, secondly, changing map of development and global poverty. It is in this new context in which new development agenda -the post-2015- will be configured, which will come to replace, and old, Millennium Development Goals. This article discusses the current state of the gestation of this post-MDG one year of approval schedule and considering that the debate on its content and government is still open. Specifically, it discusses the growing importance of inequality as part of the global development agenda and details on the possible future governance system of international cooperation which, as of today, struggling UN and OECD.
\end{abstract}

Keywords: Development, Cooperation, Poverty, Inequality, Governance, Emerging Countries.

Clasificación JEL: F35, F55, F63, O19

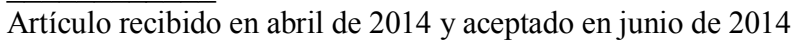

Artículo disponible en versión electrónica en la página www.revista-eea.net, ref. ə-32310 


\section{INTRODUCCIÓN}

Con 2015 como encrucijada de las agendas climática, comercial, de objetivos y financiación del desarrollo (Evans, 2014), el sistema de cooperación internacional para el desarrollo se encuentra sujeto a crecientes presiones y contradicciones para adecuar sus prioridades (objetivos) e instrumentos (financiación) a la realidad mucho más dinámica de las relaciones geoeconómicas internacionales, que ha pasado del esquema donantes/receptores, diseñado por el Comité de Ayuda al Desarrollo (CAD), al mundo de los needy donors y otros proveedores de renta media de la denominada Cooperación Sur-Sur (CSS).

En este trabajo, se analizan los elementos que condicionan este proceso de adecuación de las prioridades (que cambiarán desde la agenda de Objetivos de Desarrollo del Milenio a la de Objetivos de Desarrollo Sostenible - ODS) e instrumentos (desde la Ayuda Oficial al Desarrollo -AOD- a la financiación del desarrollo) del sistema o arquitectura de la cooperación (todavía un régimen internacional de la ayuda plagado de inercias del pasado y sobrecargado de intereses de la industria de la AOD) a las nuevas realidades internacionales. Y estas configuran un mundo que ha sido calificado sucesivamente como interpolar -con el fin de describir "la multipolaridad en la era de la interdependencia" (Grevi, 2009: 9- y posoccidental, en el que Europa y sus vástagos occidentales pierden la centralidad del poder material e ideacional/normativo (Barbé, 2013). Con el viejo sistema que se resiste a morir y el nuevo que no acaba de nacer, el momento es de crisis para unos (Domínguez, 2011; Emmerij, 2014; Ashoff y Klingebiel, 2014) y transición para otros (Kharas y Rogerson, 2012; Benzi, 2013; Janus et al., 2014).

El objetivo de este artículo es mostrar las consecuencias de la "emergencia del resto" para el desarrollo internacional y su sistema de cooperación. Concretamente, se describe el proceso de gestación y estado actual de la que se convertirá en la agenda de desarrollo global tras la finalización de los ODM en 2015, haciendo énfasis en la aparición de las desigualdades como foco y objetivo de esta agenda y en la pugna entre Naciones Unidas y la OCDE por la gobernanza del sistema de cooperación.

El artículo se estructura como sigue. En el primer apartado se realiza un análisis de la configuración mundial a partir del índice Elcano de presencia global. En el segundo apartado se analizan las profundas trasformaciones en el panorama del desarrollo internacional en términos de objetivos (con la desigualdad como nuevo tema estrella), actores (por la fuerza renovada de los países de renta media como proveedores de CSS) e instrumentos (donde una AOD modernizada se utilizará como catalizador de financiación oficial y privada del desarro1lo). En el tercero se exploran las alternativas de gobernanza de un sistema renovado que está sujeto a enormes incertidumbres por la competencia de dos plataformas denominadas en cacofonía "Alianza Global”. 


\section{2. ¿CÓMO SERÁ EL MUNDO POST-POST-GUERRA FRÍA? ALGUNAS REFLEXIONES EN TORNO AL ÍNDICE ELCANO DE PRESENCIA GLOBAL}

El índice Elcano de presencia global tiene como objetivo medir la proyección de los países fuera de sus fronteras. Sobre las bases de sus dimensiones económica, militar y blanda, calcula en qué medida los países "están ahí fuera" (Olivié et al., 2014) ${ }^{1}$. A diferencia de otros índices, como las distintas propuestas de métrica del poder $^{2}$, de compromiso con el desarrollo ${ }^{3}$, o los índices de apertura o globalización, el índice de presencia global mide (a la vez que introduce) un concepto que podría resultar útil para el análisis de las relaciones internacionales contemporáneas. Se trataría, pues, de una "métrica" de la geoeconomía y de la geopolítica que permitiera respaldar (o refutar) empíricamente la idea de que se está produciendo un cambio de eje (del Atlántico al Pacífico) del epicentro de las relaciones internacionales; en parte como cambio del mapa del desarrollo global, y con sus consecuencias para el sistema internacional de cooperación internacional para el desarrollo.

En los últimos decenios, y como consecuencia del proceso de globalización, la proyección internacional de la gran mayoría de los países (desarrollados, en declive, en transición, emergentes, en desarrollo, empobrecidos...) tiende a aumentar y este fenómeno se produce bajo muy distintos patrones de crecimiento económico, procesos y modelos de desarrollo y niveles de apertura económica. Esta creciente proyección se da independientemente de que los países ansíen el ejercicio de la influencia o del poder regional o global o de que se esté implementando una agenda de reformas y liberalización.

Cuando, a principios de 2011, elaboramos el primer ranking de países siguiendo su valor índice en presencia global (Olivié y Molina, 2011), los resultados nos parecieron, a primera vista, sorprendentes. Con la excepción de China, a los primeros puestos de los valores del índice para 2010 se aferran "viejas glorias" occidentales incluyendo los Países Bajos en el octavo puesto, Bélgica en el $13^{\circ}$ o Suiza en $16^{\mathrm{a}}$ posición. Hubiéramos pensado que la Europa decadente se posicionaría en puestos más bajos de este ranking, mientras que el Sur, el Este

\footnotetext{
${ }^{1}$ El índice es la suma ponderada de 16 variables que se agrupan en tres dimensiones o formas de presencia: económica (bienes primarios, manufacturas, servicios, energía e inversiones), militar (tropas desplegadas y equipamiento militar) y blanda (cultura, deportes, migraciones, turismo, ciencia, tecnología, educación y cooperación al desarrollo). Para más detalles sobre su metodología, véase www.globalpresence.realinstitutoelcano.org.

${ }^{2}$ Para un repaso de esta literatura, véase Olivié et al. (2014).

${ }^{3}$ Dicho compromiso sería medido con el Commitment to Development Index, elaborado por el Center for Global Development. Véase http://www.cgdev.org/initiative/commitmentdevelopment-index/index
} 
o, siguiendo la terminología de Amsden, "el resto" se posicionaría más claramente en los primeros puestos por presencia global.

Figura 1

Variaciones de presencia global (1990-2013)

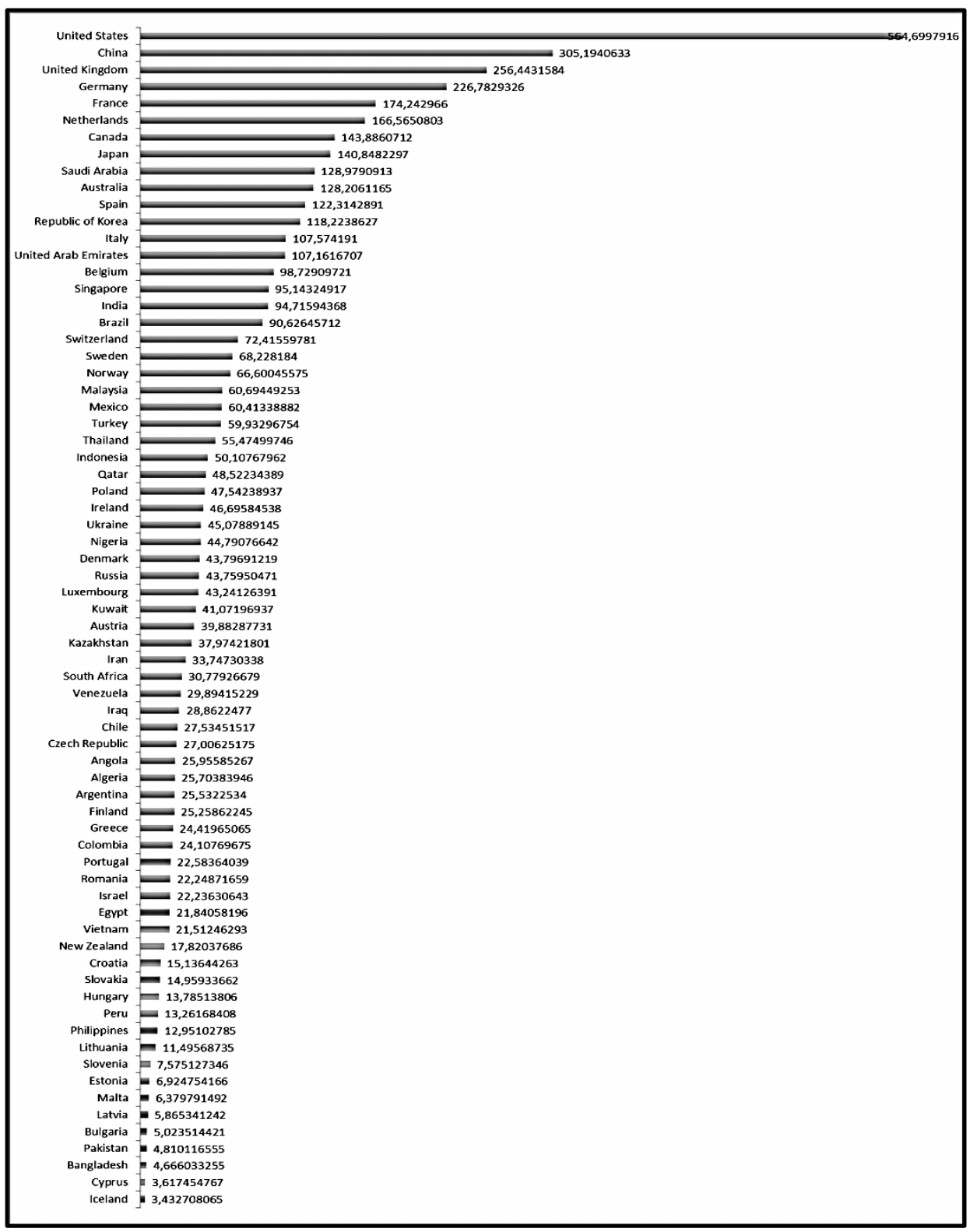

Fuente: Índice Elcano de Presencia Global, base de datos online, Real Instituto Elcano. 
Bien es cierto, en los puestos 15 a 40 sí parecían colarse emergentes de distinto tipo o región origen: BRICS en las categorías 17 (India), 20 (Brasil) y 35 (Sudáfrica), N-114, como Turquía, México, Indonesia, o Irán en los puestos 24, 25,32 y 33 , respectivamente.

Al año siguiente, además de la edición 2011 del índice, hicimos el cálculo para los años 1990, 1995, 2000 y 2005. De nuevo, y como es obvio, al finalizar la Guerra Fría, el protagonismo de Occidente en la presencia global es notorio pero la evolución de las décadas de los noventa y los 2000 sí muestra movimientos importantes a partir del puesto veinte (que se mantienen o, incluso, acentúan, en los primeros años de esta década) y, más claramente aún, en el vagón de cola. Por ejemplo, entre 1990 y 2013, Brasil escala 4 posiciones, subiendo del puesto 23 al 19, Emiratos Árabes Unidos pasa de la $56^{\mathrm{a}}$ a la $17^{\mathrm{a}}$ posición y Nigeria de la $48^{\mathrm{a}}$ a la $33^{\mathrm{a}}$.

Así, las variaciones de presencia en valor índice muestran que algunos de los emergentes son los que mayores incrementos de presencia global han registrado desde 1990. El país cuya presencia global crece en mayor medida es Estados Unidos, lo que resulta lógico si se tiene en consideración que es el que parte de un mayor valor índice en 1990 (de algo menos de 500 puntos) (Figura 1). Cabe destacar que el segundo país por incremento de presencia global es China, Ara-

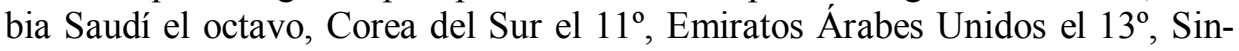
gapur el $14^{\circ}$, India el $15^{\circ}$ y Brasil el $16^{\circ}$. En definitiva, no son los emergentes los que se posicionan en los primeros puestos por presencia global pero algunos de ellos sí son los que más aumentan en valor índice por lo que, de mantenerse la tendencia, cabe esperar una consolidación de más países emergentes en el top diez de este ranking.

De hecho, los datos de 2013 reflejan el posicionamiento de China en la cuarta posición mientras que Rusia se sigue situando en la sexta y Arabia Saudí asciende hasta la $12^{\mathrm{a}}$, un puesto por debajo de España.

Por último, la crisis económica internacional puede haber agudizado este "trasvase" de presencia global del Norte al Sur y al Este. De hecho, las variaciones el valor índice de presencia global entre 2012 y 2013 muestran que, rompiendo con la tendencia de años anteriores, hay una buena parte de los países para los que se calcula el índice que ven disminuido su volumen de presencia global, mientras que los emergentes ganan terreno. Así, 44 países registran aumentos de presencia global en valor total. Siete de diez países con las mayores variaciones positivas de presencia global entre 2012 y 2013 son emergentes o en transición (Catar, China, Emiratos Árabes Unidos, Kuwait, Nigeria, Rusia, Sin-

\footnotetext{
${ }^{4}$ Bangladesh, Corea del Sur, Egipto, Filipinas, Indonesia, Irán, México, Nigeria, Pakistán, Turquía y Vietnam.
} 
gapur, Turquía) y sólo dos países occidentales aparecen en este top diez: Estados Unidos, que ocupa la cuarta posición, y Francia, en la novena (Figura 2).

Figura 2

Variaciones positivas de presencia global, en valor índice (2012-2013)

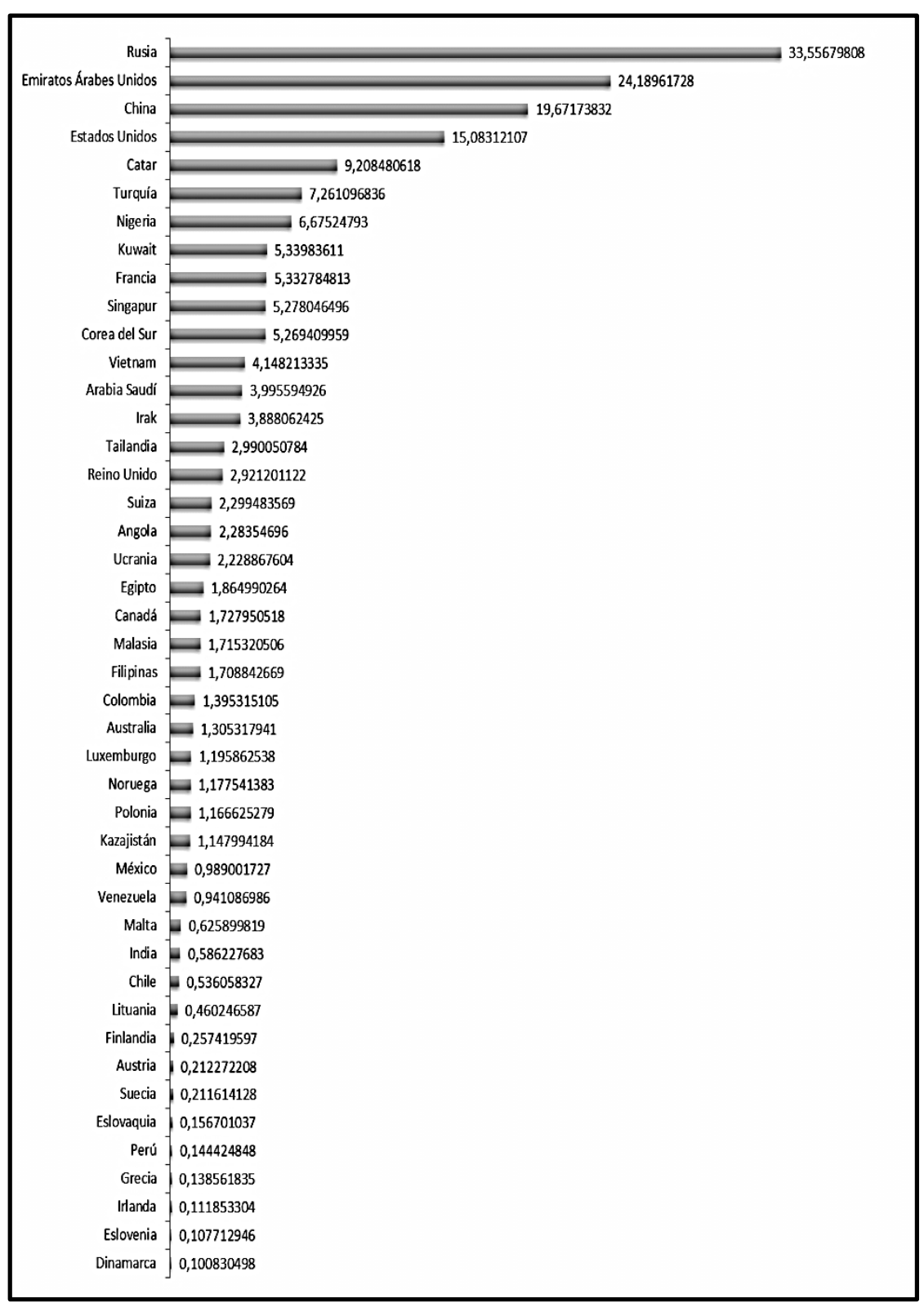

Fuente: Índice Elcano de Presencia Global, base de datos online, Real Instituto Elcano. 
Además, de los 26 países cuya presencia global se reduce respecto de 2012 , 15 son europeos y 14 miembros de la Unión Europea (Figura 3).

Figura 3

Variaciones negativas de presencia global, en valor índice (2012-2013)

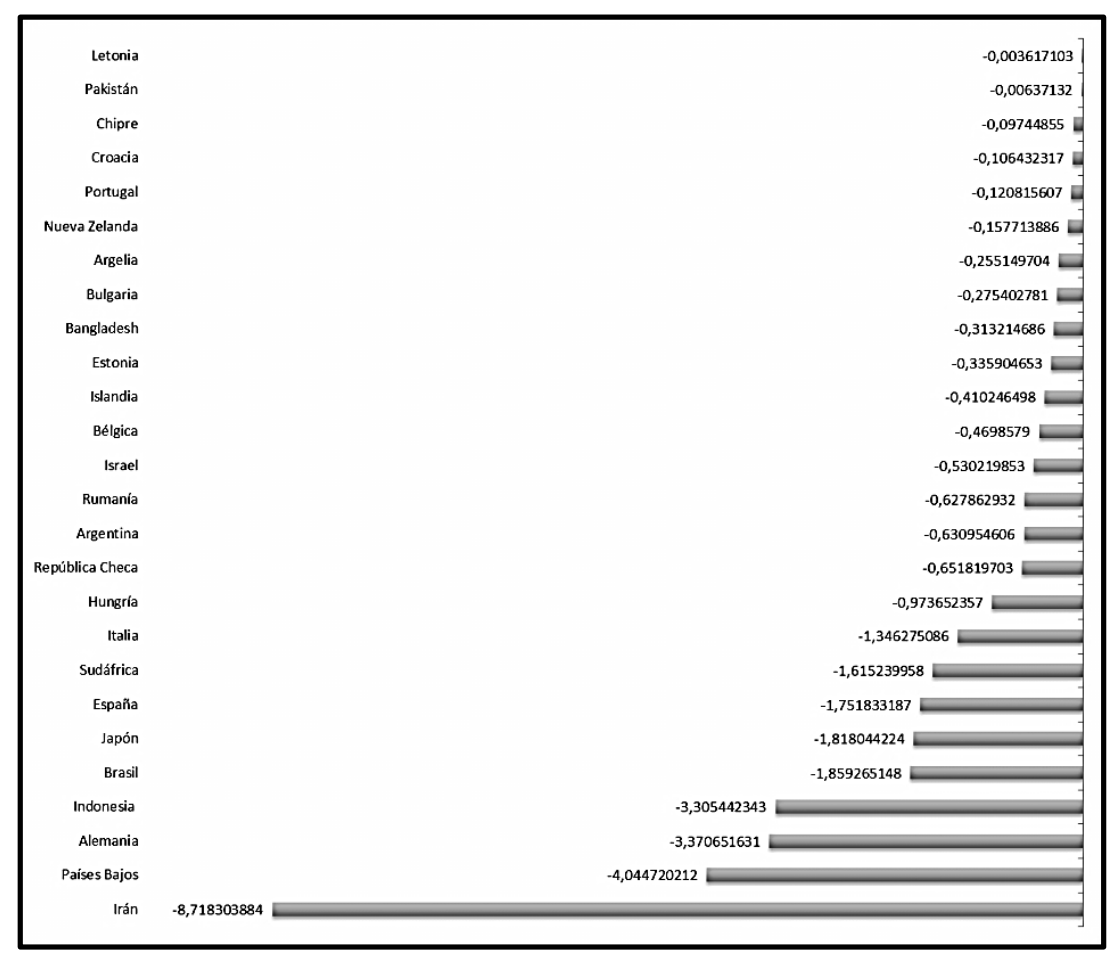

Fuente: Índice Elcano de Presencia Global, base de datos online, Real Instituto Elcano.

Los análisis sobre el eventual catching up de los países en desarrollo respecto de los desarrollados son numerosos. Sin embargo, sigue abierto el debate sobre si emerge "el resto" -lo que cambiaría la configuración del mapa del desarrollo vigente desde la revolución industrial- o si, sencillamente, hay un puñado de países que pasa del grupo de los pobres al de los ricos o si, más específicamente, ese puñado se localiza en una región en concreto -que sería, seguramente, la asiática-.

Llevado al terreno concreto de la proyección exterior de los países $-y$, por lo tanto, su capacidad, voluntad o responsabilidad en la gobernanza mundial-, los resultados del índice Elcano de presencia global sí muestran un aumento relativo del peso de las regiones en desarrollo en las relaciones internacionales, lo que podría medirse con la evolución de las cuotas de presencia de distintas regiones o países (Figura 4). 
No obstante, también se hace patente el mayor peso relativo de Asia Sur y oriental en relación a América Latina y el Magreb y Oriente medio. No solamente la cuota de partida era mucho mayor en $1990-11 \%$ en el caso de Asia Sur y oriental frente a $3 \%$ por parte de cada una de las otras dos regiones-. La ganancia de cuota también es mayor, en las últimas dos décadas, para la región asiática -cuya cuota crece hasta $17 \%$ de la presencia global total en 2013- que para América Latina (5\%) o Magreb y oriente medio (6\%).

Figura 4

Cuotas de presencia global por regiones (1990-2013)

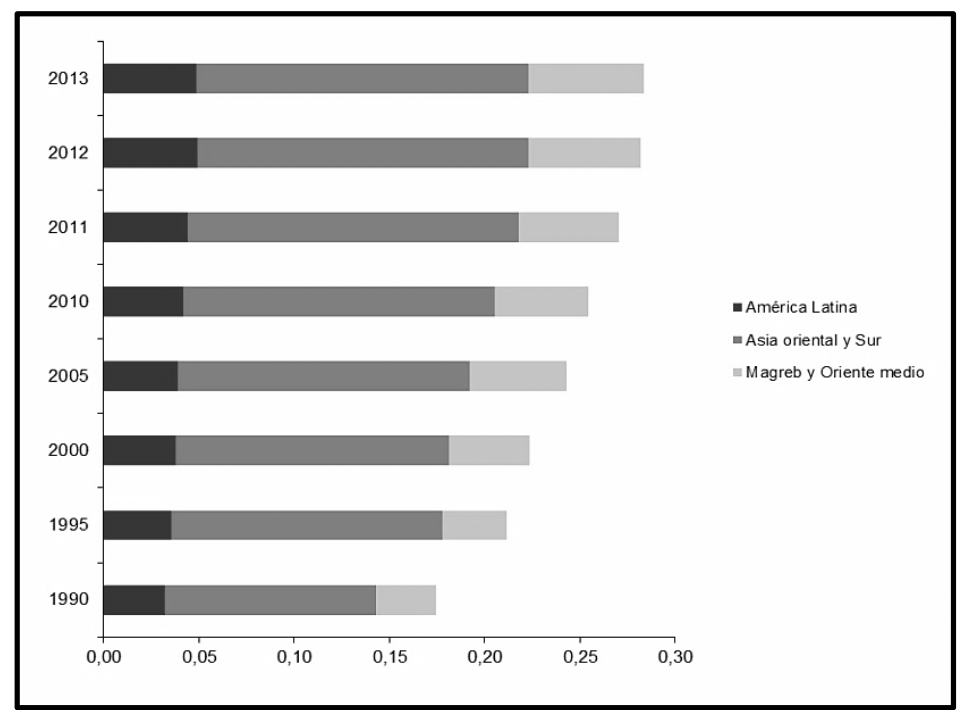

Fuente: Índice Elcano de Presencia Global, base de datos online, Real Instituto Elcano.

Este aparente patrón de concentración de las cuotas de presencia global en algunas regiones respecto de otras parece repetirse dentro de cada región. Así, en términos de presencia global, se podrían detectar con claridad líderes regionales que, además, habrían emergido en las últimas décadas, desplazando así a otros líderes de la misma agrupación. Podría ser el caso de Brasil frente a México (Figura 5), de China frente a Japón (Figura 6) o de Emiratos Árabes Unidos frente a Arabia Saudí (Figura 7). Sin embargo, es importante destacar que en Asia, a diferencia de América Latina y Magreb y Oriente medio, el auge del líder regional -China en este caso- no se produce en detrimento de las ganancias de cuota de presencia de otros países de la región. De hecho, aparte de Filipinas, Japón y Pakistán, todos los países de la región incrementan su cuota de presencia global en el periodo 1990-2013. 
Figura 5

Cuotas de presencia global por países en América Latina (1990-2013)

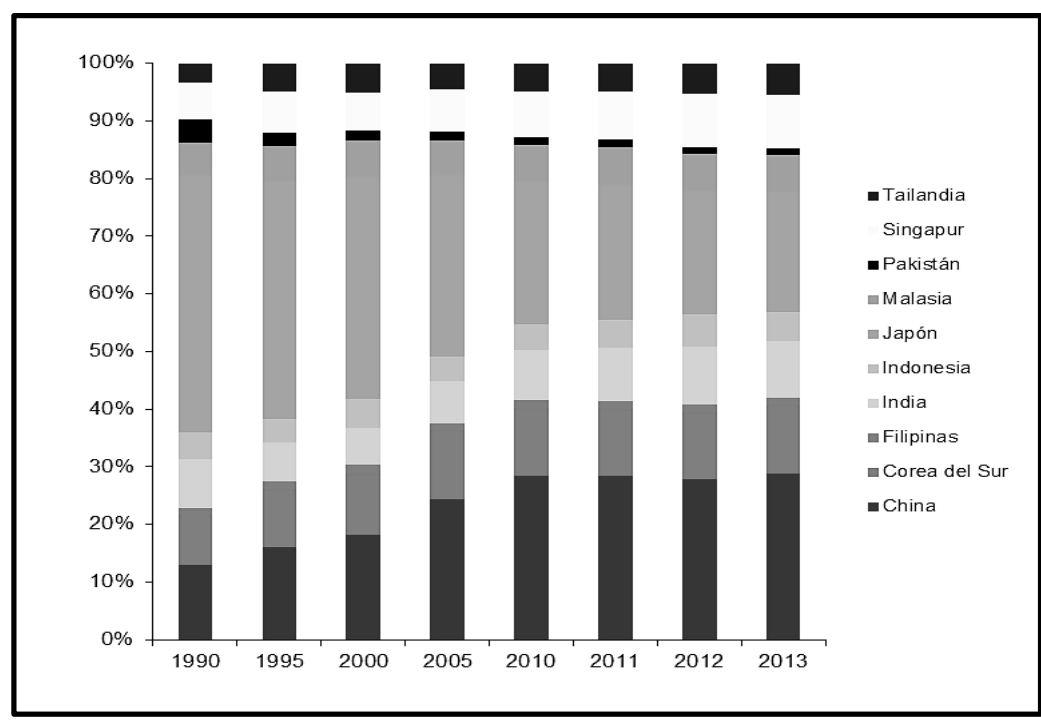

Fuente: Índice Elcano de Presencia Global, base de datos online, Real Instituto Elcano.

Figura 6

Cuotas de presencia global por países en Asia Sur y oriental (1990-2013)

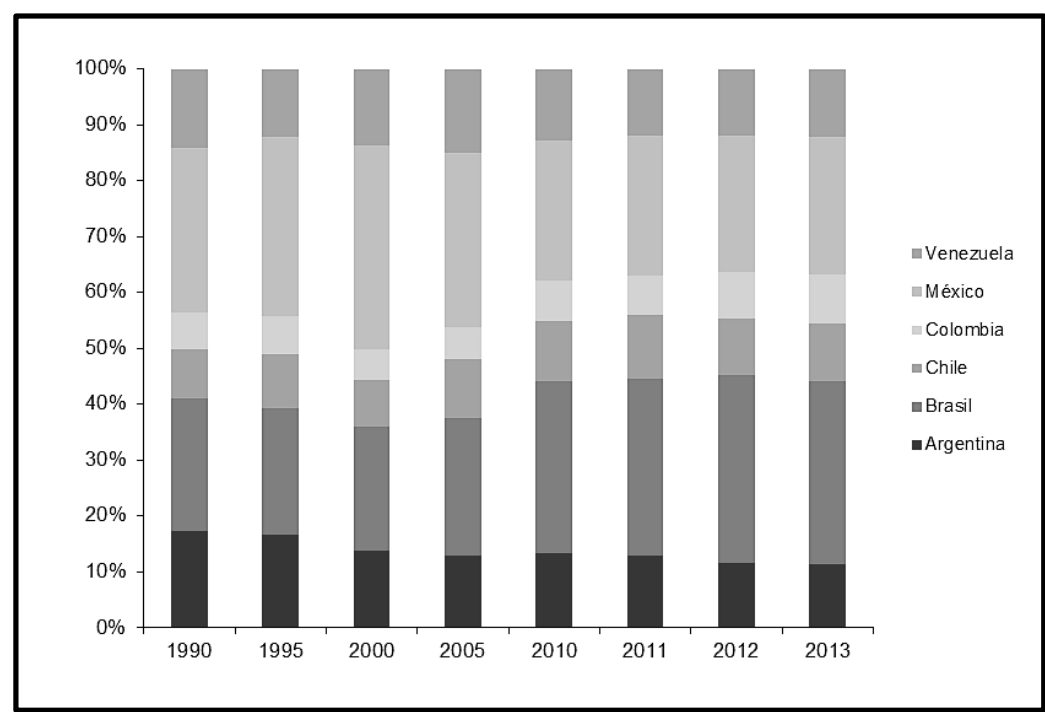

Fuente: Índice Elcano de Presencia Global, base de datos online, Real Instituto Elcano. 
Figura 7

Cuotas de presencia global por países en Magreb y Oriente medio (1990-2013)

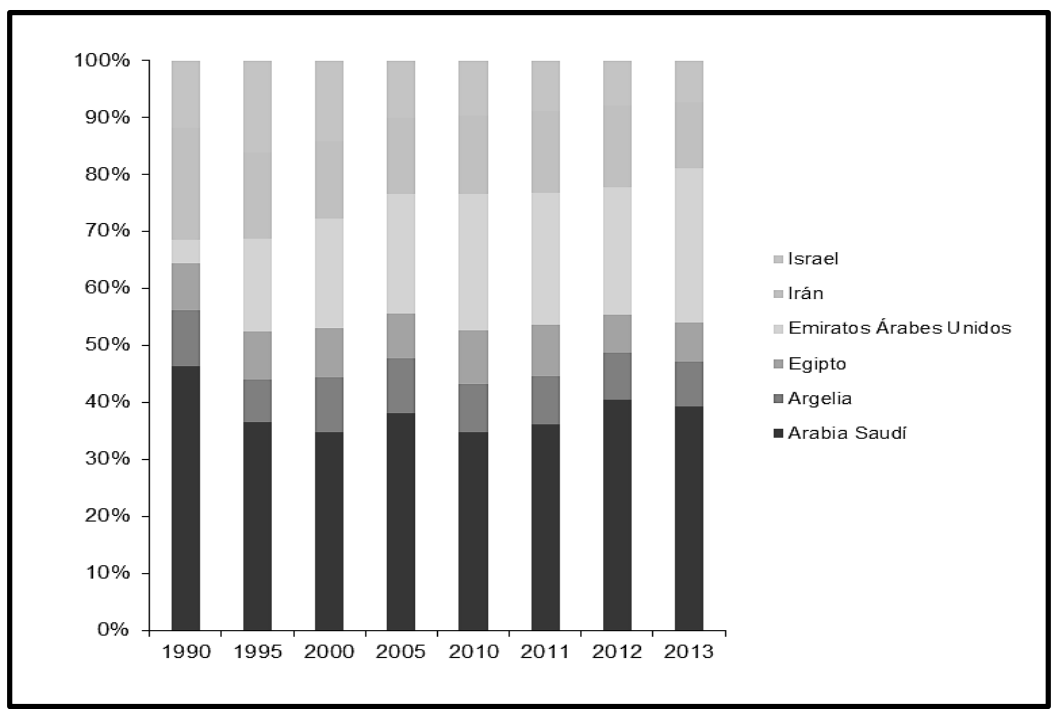

Fuente: Índice Elcano de Presencia Global, base de datos online, Real Instituto Elcano.

Como se ha señalado en ocasiones anteriores (Olivié et al., 2014), el índice de presencia global no es un índice de poder, aunque pueda ayudar a comprender cómo se distribuye el poder, entre países, a escala mundial. Hasta cierto punto, el ejercicio de la influencia o el poder deberán basarse en la cantidad y naturaleza de presencia global de cada país: un país difícilmente tendrá un papel destacado en la gobernanza mundial si no se acompaña de un cierto nivel de proyección exterior, en una serie de ámbitos. Por otra parte, en un mundo globalizado, con una proyección internacional creciente por parte de la mayoría de los países -y, por tanto, una atomización de la misma entre un número creciente de países-, posiblemente haga falta menos 'cantidad' de presencia, individualmente, para el ejercicio de la influencia.

Los resultados del índice Elcano de presencia global muestran una tendencia estructural hacia la dispersión de la proyección exterior de los países. El cálculo del índice Herfindahl-Hirschman (IHH), aplicado a los 70 países para los que se calcula el índice, muestra un proceso de desconcentración tanto en la dimensión económica como en la blanda para cada sub-periodo desde 1990; aunque la intensidad del proceso varíe de un periodo a otro, y también por dimensiones (Figura 8). Si a esto sumamos el hecho de que las cuotas combinadas de presencia de Estados Unidos y China ha tendido a reducirse desde los años noventa (Tabla 1), podría apuntarse que, al menos en términos de presencia global, el mundo podría estar encaminándose hacia una cierta apolaridad. 
Figura 8

Índice Herfindahl-Hirschman $(\mathrm{IHH})$ de concentración, por dimensiones y sub-periodos (1990-2013)

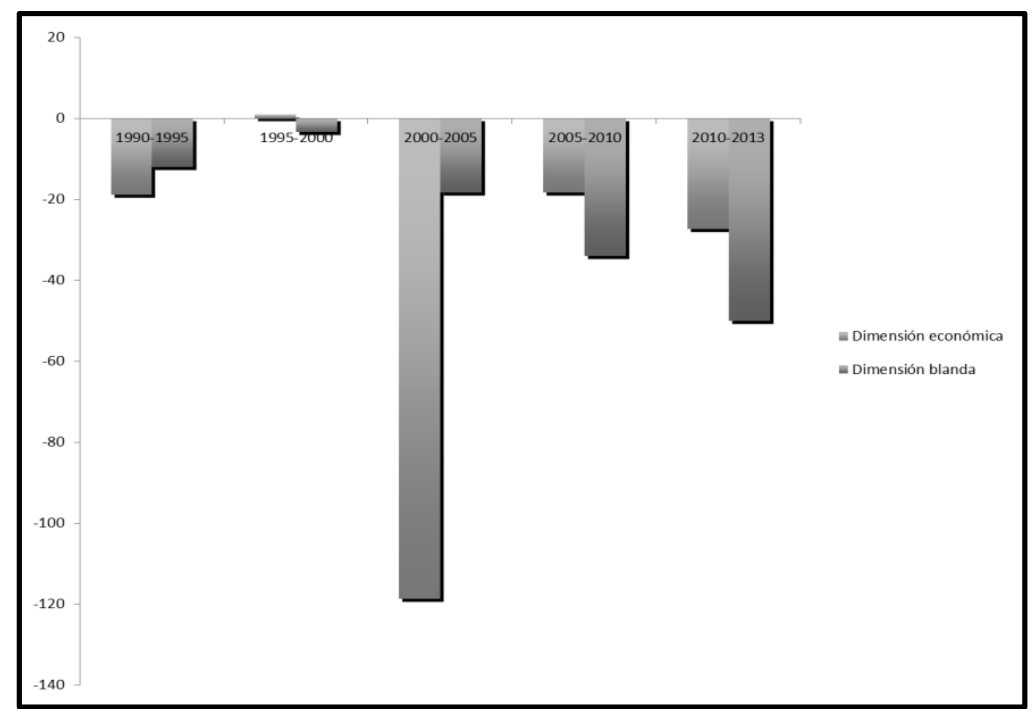

Fuente: Índice Elcano de Presencia Global, base de datos online, Real Instituto Elcano.

Tabla 1

Evolución de las cuotas de presencia global de China y Estados Unidos (en \%)

\begin{tabular}{|l|rrrrrrrr|}
\hline & $\mathbf{1 9 9 0}$ & $\mathbf{1 9 9 5}$ & $\mathbf{2 0 0 0}$ & $\mathbf{2 0 0 5}$ & $\mathbf{2 0 1 0}$ & $\mathbf{2 0 1 1}$ & $\mathbf{2 0 1 2}$ & $\mathbf{2 0 1 3}$ \\
\hline China & 1,4 & 2,3 & 2,6 & 3,7 & 4,6 & 4,9 & 4,8 & 5,0 \\
\hline Estados Unidos & 23,5 & 21,9 & 22,6 & 19,5 & 17,9 & 16,8 & 15,8 & 15,6 \\
\hline Total & 25,0 & 24,2 & 25,2 & 23,2 & 22,5 & 21,7 & 20,6 & 20,7 \\
\hline
\end{tabular}

Fuente: Índice Elcano de Presencia Global, base de datos online, Real Instituto Elcano.

Sin embargo, un análisis de los resultados en mayor detalle muestra una ralentización de dicha tendencia a la desconcentración (Figura 9). Esto ocurre a pesar de la fuerte dispersión de la presencia militar -resultado de la repatriación de tropas norteamericanas- y al (casi) estancamiento de la concentración de la presencia blanda. Así, es la dimensión económica la que está forzando este fenómeno.

¿Significa esto que la tendencia a la apolaridad o multipolaridad de las últimas décadas se estaría frenando o revirtiendo, iniciándose el camino hacia una nuevo escenario en presencia global? Como puede observarse en la Tabla 1, la combinación de cuotas de presencia global de Estados Unidos y de China muestra un cambio de tendencia: la caída continuada de 1990 a 2012 -con la excepción del periodo 1995-2000- se ha detenido, e, incluso, revertido ligera- 
mente -aumentando de $20,2 \%$ en 2012 a $20,7 \%$ en 2013 -. No obstante, es importante tener en consideración el hecho de que los nuevos datos muestran un cambio de patrón solamente para un año, razón por la cual no podemos apresurarnos a concluir que se da un cambio de tendencia más estructural.

Figura 9

Índice Herfindahl-Hirschman (IHH) de concentración, por dimensiones (2012-2013)

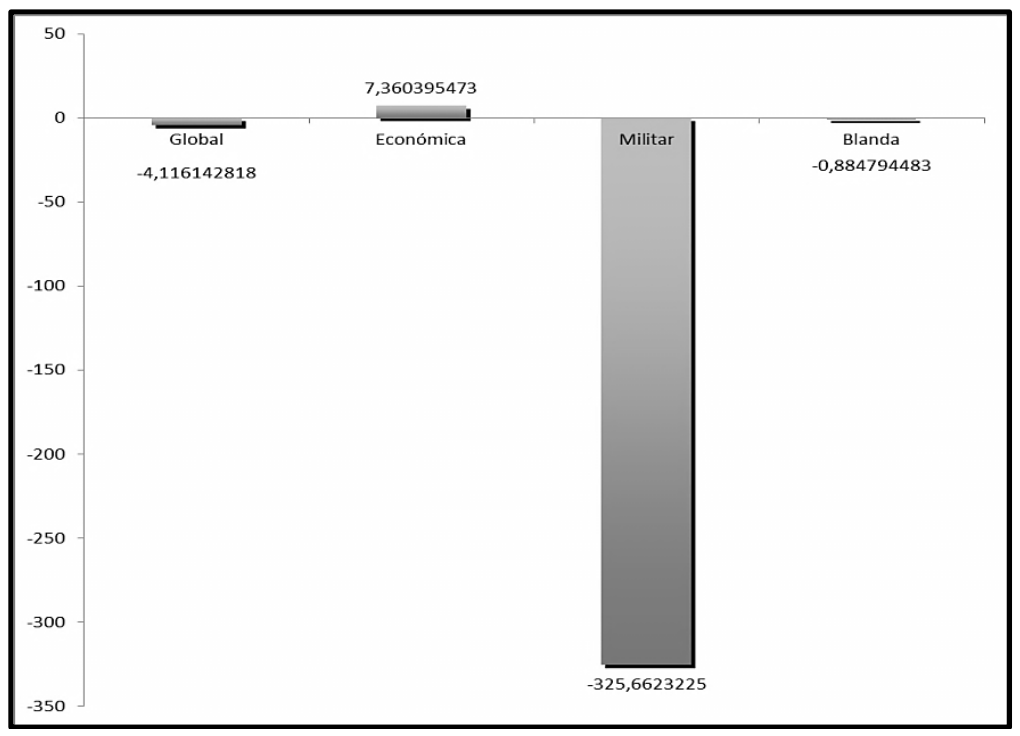

Fuente: Índice Elcano de Presencia Global, base de datos online, Real Instituto Elcano.

\section{EL NUEVO MAPA DEL DESARROLLO MUNDIAL Y DE LA AYUDA INTERNACIONAL}

Entre 1990 (la línea de base de los ODM) y 2015 (la fecha límite que se usará para evaluarlos) se han producido cambios profundos en el panorama del desarrollo internacional en cuanto a sus objetivos, actores, e instrumentos.

El objetivo de reducción a la mitad de la proporción de pobres (sobre la pobreza de línea internacional de menos de 1,25 dólares al día) ya se cumplió a nivel global hacia 2010 y quedará pendiente sólo en África Subsahariana (Olinto et al., 2013), de manera que el Banco Mundial en 2013 consideró factible erradicar ese tipo de pobreza para 2030 (sobre los supuestos de continuidad del crecimiento y no aumento de la desigualdad), incluyéndolo como uno de sus objetivos gemelos, junto con el de la prosperidad compartida (que el ingreso del $40 \%$ más pobre no aumente por debajo del ingreso per cápita de cada país) para esa fecha (Banco Mundial, 2013).

Junto a la disminución de la pobreza global, que ha sido producto del creci- 
miento económico (Dollar et al., 2013), la graduación masiva de países de la categoría Países de Renta Baja (PRB) a la de renta media (PRM) ha generado una "paradoja de la pobreza" (Sumner 2012a y 2012b), consistente en que la mayoría de los pobres globales (tanto si se los mide por las líneas internacionales de 1,25 o 2 dólares al día en paridad de poder adquisitivo, por las líneas nacionales de pobreza absolutas o relativas, o por pobreza multidimensional) ya no se concentran en los PRB, sino en los PRM (Larrú, 2013). En definitiva, la "nueva geografía de la pobreza" (Kanbur y Sumner, 2012) va a precisar una renovación del argumentario de la cooperación en congruencia con el peso que se quiere dar al mantenimiento y provisión de los bienes públicos globales en la nueva agenda de desarrollo post-2015 (Alonso, 2013; Alonso et al., 2014; Ashoff y Klingebiel, 2014).

Dado que muchos de estos nuevos PRM, junto con otros más antiguos del grupo (como Brasil o México), son activos proveedores de CSS que han roto el oligopolio de la ayuda del $\mathrm{CAD}$, esta vieja forma de cooperación entre países en desarrollo, que tanto se parece a la del CAD en sus primeros inicios -incluyendo la promoción de los intereses comerciales y las empresas del proveedor (Domínguez, 2013a; Fuchs y Vadlamannati, 2013; Breslin, 2013; Lin y Wang, 2014; Burges, 2014; Soulé-Khondou, 2014)- va a ir ganando un peso creciente en las relaciones internacionales. De hecho, el intento del CAD de modernizar la AOD (Domínguez, 2013; Hynes y Scott 2013; Morazán et al., 2014), explici-

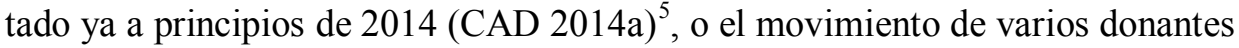
(Finlandia, Bélgica, Irlanda, Holanda, Canadá o Australia) de reformar sus ministerios de cooperación en la línea del whole of government approach (con competencias de comercio y cooperación unidas) (Emmerij 2014; Maxwell 2014), son elementos que parecen apuntar que es el CAD el que se está moviendo hacia los "otros proveedores" y no éstos hacia el CAD. Las nuevas propuestas del club de los donantes para contabilizar el apoyo oficial total al desarrollo (Total Support for Development, TOSD: AOD más otros flujos oficiales para financiar temas de paz, seguridad y lucha contra el cambio climático, junto con inversión y crédito privado para desarrollo movilizado por acciones oficiales) y repensar la cooperación (con los instrumentos del diálogo político y los acuerdos comerciales y de inversión como elementos fundamentales, más allá de la AOD) miran al modelo que practica China, que podría ser el nuevo referente al que se encamina el sistema (CAD, 2014b; Lin y Wang, 2014).

\footnotetext{
${ }^{5}$ En este documento de 27 de enero de 2014, no se habla de lo que importa en la discusión, que es si junto a la AOD se contabilizará la ayuda climática (OCA en sus siglas en inglés) y la ayuda militar (OSA), aunque se hace notar que "en cualquier caso hay un fuerte interés en explorar un tratamiento ampliado de las seguridad como fortalecedora del desarrollo y una posible extensión de la cobertura de tales actividades en la AOD. La medición de la financiación climática será discutida también" y su inclusión dentro de la nueva definición dependerá "de las decisiones sobre el tratamiento de los créditos" (CAD, 2014a: 7).
} 
En todo caso, la heterogeneidad de estilos de "los otros proveedores" pone de relieve una falta de coordinación que impide considerar la CSS como sistema o régimen internacional. En realidad son relaciones de cooperación fragmentadas en varias ligas: una la liga mayor, integrada por los BRICS, que bajo el liderazgo de los BASIC (Brasil, Sudáfrica, India y China) están buscando un espacio separado para su cooperación global, que en todo caso mantiene un frágil equilibrio entre complementariedades, para conseguir una identidad común, y competencia; y la segunda liga, integrada por países como Indonesia, Malasia, Tailandia, Turquía, México, Chile, Colombia o Perú, que estarían más dispuestos a operar en esquemas sucesores de las reglas y disciplinas estadísticas y de programación y evaluación del CAD, lo mismo que los países árabes que reportan al CAD. Fuera de ambas ligas, operarían países muy motivados ideológicamente dentro del G77, como Cuba o Venezuela, con un enfoque autónomo, básicamente regional y contra-hegemónico (Mielniczuk, 2013; Olivié y Domínguez, 2013; Evans, 2014).

En un mundo con menos pobres en términos absolutos pero más pobres en términos relativos (Chen y Ravallion, 2012; Ravallion, 2012), la CSS seguirá teniendo un papel complementario de una AOD modernizada para los PRB que queden y, sobre todo, habrá que reorientar la cooperación para apoyar el crecimiento con equidad que aborde el problema de la distribución nacional del ingreso (y las oportunidades) ante las rampantes y/o persistentes desigualdades internas que afectan con mayor intensidad a los PRM por encontrarse en el tramo ascendente o la meseta de la curva en U invertida de Kuznets, según los datos y el análisis de Alvaredo y Gasparini (2013).

$Y$ es que la desigualdad se ha erigido rápidamente en la nueva diana del juego del desarrollo (Melamed, 2014) tanto en lo países emergentes/en desarrollo como en los países desarrollados: si en la práctica totalidad de los países de la OCDE para los que existen datos las desigualdades han aumentado desde 1980 a la actualidad, en el 60\% de los países en desarrollo para los que dispone de información se ha producido también un aumento (como promedio el índice de Gini ha pasado del 37,2 en 1980 al 39,4 en 2010) (Cornia y Martorano, 2013; Alvaredo y Gasparini, 2013; FMI, 2014). En todo caso, es obvio que muchos donantes europeos tendrán problemas para conciliar sus actuaciones internas, que están erosionando a la clase media y desprotegiendo a los más vulnerables, con el discurso a favor de la reducción de las desigualdades en los países en desarrollo o la nueva filosofía de la prosperidad compartida del Banco Mundial (2013), el otro objetivo gemelo para 2030, lo que abre un nuevo frente en la retórica performativa de la coherencia de políticas.

En efecto, en paralelo al debate sobre dónde vivirán los pobres hacia 2030 (la fecha de consenso para evaluar la agenda post-2015), la prioridad es cómo abordar el objetivo más amplio de reducir las desigualdades dentro de los paí- 
ses; desigualdades que se han convertido en el mayor riesgo global en términos de probabilidad desde 2012 hasta el presente (WEF, 2014), una vez que las disparidades entre países habrían disminuido según los datos aportados por Milanovic (2012). En concreto, el concepto 2 de desigualdad (desigualdad entre países ponderada por la población de los países) ha caído intensamente desde 1990, y el concepto 1 (desigualdad entre países sin tener en cuenta el diferente peso de la población), que era más bajo, también ha disminuido desde 2000, para acabar ambas en aproximadamente el mismo nivel de coeficiente de Gini hacia 2010 (Milanovic, 2012; Edward y Sumner, 2013). Esta es la otra paradoja del mundo posoccidental: la "paradoja de la desigualdad" (Norton, 2012: 9), en medio de la cual los países graduados como PRM, incluyendo los que son ahora potencias (re)emergentes -y que concentrarán en 2030 la mayoría de los pobres, pero también una proporción muy elevada de la clase media mundial (Sumner, 2012d)- estarán en condiciones de movilizar recursos internos para el desarrollo, ya que la brecha de pobreza calculada como porcentaje de su respectivo PIB se podría situar en 2020 en $0,3 \%$ para 1,25 dólares y 1,2\% para 2 dólares al día en el escenario de crecimiento moderado ${ }^{6}$.

Si como muestra Ravallion (2005: 7) "la desigualdad es mala para los pobres" ("cuanto mayor es la desigualdad inicial en un país, menor proporción de las ganancias del crecimiento compartirán los pobres"), la conclusión obvia es que el crecimiento reduce la pobreza más rápido en países con distribuciones menos desiguales del ingreso y, por tanto, es importante combatir la desigualdad para reducir la pobreza. Esto significa que los países más desiguales necesitan crecer mucho más deprisa para reducir su pobreza, lo que choca con el efecto de que la desigualdad puede ser "destructiva para el crecimiento, por ejemplo, ampliando el riesgo de crisis o dificultando a los pobres invertir en educación" (Berg y Ostry, 2011: 3). Es más, parece comprobarse que la duración de los períodos de crecimiento está asociada directamente y de manera robusta con la mayor igualdad en la distribución del ingreso, de forma que la "atención a la desigualdad puede traer beneficios significativos a largo plazo para el crecimiento" (Berg y Ostry, 2011: 3) y, como acaba de reconocer el FMI (2014: 4), "los altos niveles de desigualdad son dañinos para la senda y sostenibilidad del crecimiento".

En definitiva, todo parece indicar que el abordaje de las desigualdades internas de ingresos y oportunidades (todavía más dañinas para el crecimiento que

\footnotetext{
${ }^{6}$ Para los países que queden como PRB, el esfuerzo sería del 7\% para 1,25 dólares constantes al día (en paridad del poder adquisitivo de 2005) y del 21,1\% para 2 dólares. Las cifras para 2030 en el mismo escenario serían de $0,2 \%$ y $0,6 \%$ para los PRM, y $7,3 \%$ y $22,2 \%$ para los que queden como PRB (Sumner 2012b y 2012c). Kharas y Rogerson (2012) realizan una estimación diferente, asumiendo que si en 2025 los países en desarrollo proveen el equivalente al 1\% de su PIB para la reducción de la brecha de pobreza, bastará con un $0,3 \%$ del PIB de los países del $\mathrm{CAD}$ para cerrar dicha brecha.
} 
las del ingreso, véase Molina et al., 2013) podría situarse en el "corazón" de la nueva agenda post-2015, aunque sea indirectamente a través de las políticas de ensanchamiento de la clase media, que es lo que mide el denominador del índice de Palma (el acumulado de los dos primeros quintiles de la distribución del ingreso, o $40 \%$ más pobres), ahora recuperado por la agenda de la prosperidad compartida del Banco Mundial (Rosenblat y McGavock, 2013).

Este desplazamiento del foco de atención desde la pobreza identificada con países (desigualdades internacionales) hacia la pobreza dentro de los países (desigualdades dentro de los países) ha demandado una nueva narrativa sustitutiva de la vieja metáfora Norte-Sur que la OCDE está construyendo a marchas forzadas con su mundo de cuatro velocidades en el que se combinan tipologías de ingreso con tasas de crecimiento (OCDE, 2011), en un intento de superar las viejas categorías de países desarrollados y países en desarrollo propia del régimen tradicional de la ayuda de la Guerra fría y que ha quedado superada con esa "reSURrección" de la que habla Benzi (2013: 14) o en los equilibrios que representan organismos como el G-20.

El relato superador de la metáfora Norte-Sur, que ahora se propone en este contexto muy diferente de financiación del desarrollo, trata de una nueva geografía mundial. Dicha geografía refleja los cambios operados en la economía internacional como consecuencia del crecimiento económico, algunos desde la caída del muro de Berlín y en otros casos desde el final de la segunda guerra mundial, de un grupo selecto de países en desarrollo del entonces llamado Sur, que se convirtieron en economías emergentes, y cada vez más influyentes por la combinación de peso demográfico y rápido crecimiento del PIB. Estos países pasaron de "economías emergentes y en desarrollo", según la terminología del FMI acuñada en 2004 (Nielsen, 2011), a convertirse en verdaderos "polos de desarrollo" (Banco Mundial, 2011; G-20, 2011). Las proyecciones del Banco Mundial para 2030 indican que los países en desarrollo "serán la fuerza dominante en la economía global" (Banco Mundial, 2011: 400), con una contribución de dos tercios al crecimiento económico mundial, un cuarto del total atribuible a China, que para entonces ya se habrá convertido en PRA (OCDE, 2013a; Morrison, 2014).

Precisamente, la OCDE afirma la existencia de "un cambio estructural de significado histórico", producto del "desplazamiento de la riqueza" hacia los países no OCDE, que pasarán de contribuir el 38\% del PIB mundial (en PPA) en 1990 al 57\% en 2030 (OCDE, 2010a). Un mundo que marcha a cuatro velocidades (una metáfora acuñada en 2007 por James Wolfensohn) donde la mayoría de los países emergentes y en desarrollo convergen con el club de los países "afluentes" (los PRA en la clasificación del Banco Mundial). Esta noción de convergencia es para la OCDE un dato que se deriva de dos hechos: el gran aumento del número de PRB y PRM cuyas tasas de crecimiento del PIB per 
cápita han sido más del doble (más de $3,75 \%$ de crecimiento anual durante los noventa y más del 1,8 durante los 2000) que la de los países afluentes; y la disminución del número de países "pujantes" o struggling (PRM con tasas de crecimiento del PIB per cápita de menos del doble que la de los países afluentes) y "pobres" (PRB con tasas de crecimiento del PIB per cápita de menos del doble que la de los países afluentes), intercambiándose la situación relativa de convergentes frente a pujantes y pobres en los últimos veinte años (Olivié y Domínguez, 2013).

En todo caso, aunque la propia OCDE (2012) prevé que el proceso de convergencia OCDE/no OCDE continuará en el período 2011-2030 (con tasas de crecimiento del PIB per cápita en PPA del 5,2\% para los segundos frente al $1,7 \%$ de los primeros) consolidando cambios de calado en la distribución del poder económico mundial, esta visión, que también comparten el Banco Mundial (2012) y el FMI (Bluendorn et al., 2013), no niega que haya margen para seguir cooperando entre los dos mundos, porque las distancias relativas serán todavía muy grandes en el futuro: en 2060 se proyecta que los países no OCDE tendrán un PIB per cápita entre un 75 y un $40 \%$ inferior al de los líderes de la OCDE (2012).

\section{LA NUEVA GOBERNANZA DE LA COOPERACIÓN Y DE LAS POLÍTICAS DE DESARROLLO}

2015 va a marcar un antes y un después también en la gobernanza de la cooperación, que lo primero que deberá es ir más allá de la definición de arquitectura de la ayuda ("un conjunto de reglas e instituciones que gobiernan los flujos de ayuda a los países en desarrollo") dentro de ese "importante área de la política pública" que es la cooperación internacional para el desarrollo según el CAD (OCDE, 2010b). Si con Busan se pasó de la agenda de eficacia de la ayuda a la de eficacia del desarrollo, el problema es que la Alianza Global para la Cooperación Eficaz al Desarrollo (AGCED), pese a conseguir la adhesión de 161 países (entre ellos la anhelada de los "otros proveedores", los BRICS, o Indonesia del grupo de los enforced enhacement de la OCDE que incluye a los anteriores sin Rusia), tiene un incierto futuro como consecuencia del pecado original de nacimiento. La AGCED no deja de ser producto de la semilla del CAD a través de su autoliquidado Working Party on Aid Effectiveness (WPEFF) y añade a esa debilidad el estrepitoso fracaso de la evaluación de la Declaración de París, que obligó in extremis a salvar la declaración final del IV Foro de Eficacia de la Ayuda de Busan (Atwood, 2012).

Toda la estrategia del CAD desde 2011 para atraerse a sus disciplinas y métricas a los proveedores de CSS (Olivié coord., 2011) quedó frustrada en gran parte por la no participación en el comité directivo de la AGCED de los BRICS, que han ido reforzando su coordinación global y en 2013 plantearon la creación 
de su propio banco de desarrollo en un claro desafío a las instituciones herederas de Bretton Woods (Cooper y Faroq, 2013) de las que el CAD sigue siendo visto con razón como un exponente no menor.

Por tanto, la pregunta de quién gobernará el sistema de cooperación internacional después de 2015 tiene una respuesta muy incierta y se puede resumir en la competencia o la complementariedad (subordinada) de dos alianzas: la que todavía mece la mano de la OCDE-CAD y la que saldrá de los procesos intergubernamental (Grupo de Trabajo Abierto) y de NNUU para la fijación de la agenda de ODS. La primera, la AGCED, nació con una enorme fragilidad porque la suma en el último minuto, tras arduas negociaciones, de países como China e India se hizo sobre la base de compromisos diferenciales arropados con la cláusula de la voluntariedad, lo que les exime de seguir los principios de alineamiento y armonización subsistentes de la Declaración de París que quedan sólo como aplicables dentro del sistema de cooperación del CAD. La lógica subyacente de la Declaración de Busan (facilitar la integración a dos velocidades de los sistemas CAD y CSS-BRICS, cuyos miembros comparten sillas en el G-20) ha fracasado por la no participación de los BRICS en el comité directivo de la AGCED: Indonesia (que compartía la co-presidencia y su sustituto, México) o Perú (que ocupa la silla de proveedores/receptores de cooperación) no son Chindia o Brasil.

La AGCED, que parte del principio de asociación incluyente para dar entrada a los proveedores de CSS y al sector privado, tiene el problema adicional de que, a diferencia de los miembros del CAD y de la sociedad civil, esos nuevos actores que aseguran la diversidad del nuevo paisaje de la cooperación no han articulado en cada caso una posición común: ni los BRICS ni el sector privado son patrocinadores de sus respectivas materias (los building blocks de CSS y sector privado) $\mathrm{y}$, de hecho, no figuran como patrocinadores de ninguno de los 8 building blocks para desarrollar el postBusan.

En un documento reciente de noviembre de 2013 la OCDE (2013b) señalaba los propósitos principales de la AGCED pero alcanzarlos parece a día de hoy una misión imposible. El primero de esos propósitos es mantener y reforzar el momentum político para una cooperación al desarrollo más efectiva, lo cual resulta poco creíble a tenor del déficit de financiación del secretariado técnico de la AGCED (la parte que le toca al PNUD); más bien indica una falta de interés político y expectativas a la baja antes y después de la reunión ministerial en México (Foro de Alto Nivel de la AGCED), que se retrasó del último trimestre de 2013 a abril de 2014 (Tran, 2013; Glennie, 2014), y que frente a los 6.000 participantes acreditados de Busan sólo llegó a los 1.500. El segundo propósito es asegurar la mutua responsabilidad para la implementación de los principios de Busan, lo que choca con las consideraciones anteriores y la resistencia de los donantes a utilizar el apoyo presupuestario y la falta de participación de los 
BRICS que no quieren ser socializados en el estilo de cooperación del CAD (el cual, en la práctica, estructuró la agenda del Foro de México; véase CAD, 2014c), para evitar un deterioro de su imagen de cooperantes del y para el Sur (Olivié y Domínguez, 2013; Cabral et al., 2014). El tercero es el intercambio de conocimientos y lecciones aprendidas, pero en este punto la AGCED sigue viéndose como un organismo de la OCDE por parte de los países del G77 (Tran, 2013), algunos de ellos como Cuba y Venezuela con cooperaciones cuyos montos son muy elevados (la cooperación compensada cubana, como auténtico rubro de exportación de servicios médicos y sanitarios con cifras de 9 ceros, lo mismo que la venezolana con sus préstamos concesionales ligados a la compra de petróleo a través de Petrocaribe) que no firmaron la adhesión a la AGCED. Y finalmente, el cuarto propósito es el apoyo a la implementación de los principios de Busan a nivel país; en este punto el déficit de financiación, la resistencia de los donantes a hacer un uso más intenso del apoyo presupuestario y el principio de voluntariedad amenazan claramente ese objetivo: sólo 46 países receptores han participado en la encuesta de monitoreo de Busan frente a los 86 que se sometieron a la evaluación de la Declaración de París en 2010 (CEPEI, 2014), de manera que la supuesta ganancia en legitimidad sobre la estructura anterior (WP-EFF) se ha visto contrarrestada con la pérdida de eficacia y relevancia (Janus et al., 2014).

$Y$ es que el protagonismo en el proceso post-2015 (que conecta con los grandes debates del desarrollo) le corresponde a la otra Alianza Global, la que parte del ODM8 ("Alianza Global para el Desarrollo"), una vez que las agendas de lucha contra la pobreza y desarrollo sostenible van a ser integradas en la Nueva Alianza Global para el Desarrollo Sostenible. Ello está explicitado en los dos informes clave del proceso de NNUU -el del Grupo de Alto Nivel de Personas Eminentes (GANPE, 2013) y el del Secretario General de NNUU (SGNNUU, 2013)- y también en el de la Red de Soluciones para el Desarrollo Sostenible (Sachs dir., 2013). En todo caso, tanto el contenido de los ODS como el mecanismo de financiación y gobernanza de la nueva agenda dependerá de los resultados del proceso intergubernamental que se lleva a cabo a través del Grupo de Trabajo Abierto de la Asamblea General sobre los ODS (formado por 30 países, pero en el que han participado ya 70 gracias a un sistema de delegación) con el apoyo del Comité Intergubernamental de Expertos sobre Financiación del Desarrollo Sostenible (que deberán reportar a la Asamblea General en septiembre de 2014), ya que algunos países como China (con una gran influencia sobre el G77) o Brasil (que actúa como facilitador del Foro de Alto Nivel Político sobre Desarrollo Sostenible) desconfían del GANPE y prefieren mantener la negociación a nivel intergubernamental (Evans y Steven, 2013a y 2013b; Steven, 2013; Jiang y Fues, 2014).

Aunque algunos siguen manteniendo que el Foro de Cooperación al Desarrollo del ECOSOC podría asumir el papel clave en la gobernanza de los ODS 
(en julio de 2014 se reunirá para "valorar cómo la Alianza Global para el Desarrollo post-2015 podría trabajar en la práctica"), lo cierto es que su efectividad es limitada y carece de mandato para ello (Janus et al., 2014). En cambio, el mandato de Río+20 fue no solo crear el Grupo de Trabajo Abierto, sino un Foro de Alto Nivel Político sobre el Desarrollo Sostenible (FANPDS), que sustituyó a la Comisión de Desarrollo Sostenible. Por tanto, corresponde a este nuevo mecanismo intergubernamental, que mantuvo su primera reunión en 2013, fijar en septiembre de 2015, cuando celebrará la segunda y decisiva reunión para la fijación de los ODS (a nivel de Jefes de Estado y de Gobierno, que luego se repetirá cada cuatro años) concretar la fecha de la conferencia sobre la financiación de los mismos (prevista inicialmente para antes del segundo FANPDS, aunque al final podría retrasarse hasta 2016 en una repetición del juego ODM primero y Monterrey después), junto con el mecanismo de gobernanza de la agenda que aúne los principios de legitimidad, eficacia y relevancia (Evans y Steven, 2013a y 2013b; Evans, 2013 y 2014; Janus et al., 2014).

La pregunta es si será posible una articulación entre estas dos alianzas, la AGCED y la que surja del FANPDS. Para algunos autores cabe una lógica de división del trabajo y complementariedad entre ambas (Besharati, 2013; Kim y Lee, 2013). Por el contrario, parece necesario tomar en consideración que las debilidades apuntadas de la AGCED (como heredera del CAD-OCDE con la falla constitutiva de los compromisos voluntarios de Busan, la desafección de los BRICS y otros emergentes, la baja respuesta de los receptores y, en definitiva, la obsolescencia de la agenda de eficacia de un instrumento, la AOD, que posiblemente será superado por los acontecimientos) junto con su desplazamiento de misión (mission creep) aprovechando la cacofonía "Alianza Global" (Glennie, 2014; Janus et al., 2014), vuelven a plantear el déficit de legitimidad de input, de proceso y de output que ya se señaló al momento de su fundación (Kindornay y Samy, 2012). A pesar de la ampliación acordada en la $5^{\text {a }}$ reunión del comité directivo de la AGCED con 6 sillas a añadir a las 18 (con un representante adicional para África y los provedores/receptores de cooperación, y la entrada de un representante por los donantes árabes), la sustitución de Indonesia por México en la co-presidencia (otro país de la OCDE), acordada finalmente en abril pasado durante el Foro de Alto Nivel de la AGCED, no contribuirá a cerrar ese déficit y, por tanto, salvo sorpresa de última hora (que uno de los BRICS se integrara en la nueva silla libre de los proveedores/receptores), es probable que la supervivencia de la AGCED pase por convertirse en mecanismo auxiliar de la Nueva Alianza Global para el Desarrollo Sostenible amparada por NNUU (CEPEI, 2014). De otro modo, la alternativa de convivir por su cuenta la convertiría en un mecanismo cada vez menos relevante, mientras que un reparto horizontal de funciones con la Nueva Alianza Global generaría el peligro de forum shopping, característico de la fragmentación del multilateralismo zombi o de mínimo común denominador actual (Rinke y Schnekener, 2012; Evans 2014; 
Janus et al,. 2014).

\section{CONSIDERACIONES FINALES}

Este artículo ha tratado de resumir el proceso de gestación de la agenda de desarrollo global explicando cómo las desigualdades -un tema tabú en los debates sobre desarrollo desde los años ochenta- comienzan a configurarse como un elemento clave de dicha agenda y explicando, con un enfoque de economía política, la actual pugna entre las Naciones Unidas y la OCDE por el gobierno del sistema de cooperación internacional para el desarrollo.

Es prácticamente imposible concluir un artículo de estas características sin recurrir al tópico de que las relaciones internacionales y el sistema de cooperación internacional para el desarrollo se encuentran ahora en un momento minado de incertidumbres. Ni el mundo, ni el mapa del desarrollo, ni el sistema de cooperación al desarrollo serán dentro de cinco años los que eran hace cinco; pero no podemos siquiera apuntar a qué se parecerán.

Es importante, sin embargo, insistir en la magnitud y distinta naturaleza de dichas incertidumbres. En primer lugar, no sabemos si el mundo se está encaminando hacia la apolaridad o si, por el contrario, se está conformando una nueva forma de bi o multipolaridad en la que alguna vieja potencia, como Estados Unidos y/u otro gran emergente, como China, liderarían un proceso de globalización con un nuevo sistema de gobernanza mundial. En segundo lugar, ignoramos cuál será el punto de llegada de un nuevo mapa del desarrollo en el que las desigualdades se convertirán, previsiblemente, en la característica compartida por países con muy desiguales patrones y niveles de desarrollo. En este sentido se suman, además, los interrogantes sobre la salida de la crisis de la Europa occidental y las dudas sobre la sostenibilidad de los ritmos de crecimiento de las economías emergentes. En este contexto, sin claridad alguna sobre si alguien liderará las relaciones internacionales, ni si podremos seguir clasificando los países en (nuevos) ricos y (nuevos) pobres, resulta prácticamente imposible saber, a fecha de hoy, cuál será el alcance de la agenda post 2015, quien influirá decisivamente en su diseño, con qué respaldo internacional contará y qué países estarán dispuestos a seguirla.

\section{REFERENCIAS BIBLIOGRÁFICAS}

ALONSO, J.A. (2013). "Cooperación con países de renta media: un enfoque basado en incentivos", Documentos de Trabajo Cooperación Española, 01/2013, AECID, diciembre.

ALONSO, J.A. et al. (2014). "Recipients and Contributors. Middle income countries and the future of development cooperation", http://effectivecooperation.org/wordpress/wp- 
content/uploads/2014/04/Recipients-and-Contributors-MICs-and-the-future-ofdevelopment-cooperat....pdf [Último acceso en abril de 2014]

ALVAREDO, F. y GASPARINI, L. (2013). "Recent Trends in Inequality and Poverty in Developing Countries", Documento de Trabajo CEDLAS, 151, Universidad Nacional de la Plata, noviembre.

ASHOFF, G. y KLINGEBIEL, S. (2014). "Transformation of a Policy Area. Development Policy Is in a Systemic Crisis and Face the Challenge of a More Complex System Environment", Discussion Paper, 9/2014, German Development Institute.

ATWOOD, B. (2012). "Creating a Global Partnership for Effective Development Cooperation", Center for Global Development Essay, octubre.

BANCO MUNDIAL (2011). Global Development Horizons 2011. Multipolarity: The New Global Economy. Washington DC: The World Bank.

BANCO MUNDIAL (2012), China 2030. Building a Modern, Harmonious, and Creative High-Income Society. Washington DC: World Bank / Development Research Center of the State Council PRC.

BANCO MUNDIAL (2013). The World Bank Group Goals. End Extreme Poverty and Promote Shared Prosperity. Washington: The World Bank.

BARBÉ, E. (2012). "La UE frente a la emergencia de un mundo posoccidental: en busca del prestigio perdido", Revista CIDOB d'Affers Internationals, 100, pp. 91-112.

BENZI, D. (2013). "Via crucis de la cooperación internacional: ¿crisis terminal o resurrección", Íconos. Revista de Ciencias Sociales, 47, pp. 9-14.

BERG, A.G. y OSTRY, J.D. (2011). "Inequality and Unsustainable Growth: Two Sides of the Same Coin?", IMF Staff Discussion Note, 11/08, abril.

BESHARATI, N.A. (2013). "A Year after Busan: Where is the Global Partnership Going?", Ocassional Paper, 136, South African Institute of International Affairs, febrero.

BLUEDORN, J. et al. (2013). "The Growth Comeback in Developing Economies: A New Hope or Back to the Future?", IMF Working Paper, 12/132, mayo.

BRESLIN, S. (2013). "China and the South: Objectives, Actors and Interactions", Development and Change, 44 (6), pp. 1276-1294.

CABRAL, L. et al. (2014). "Brazil and the Shifting Consensus on Development Cooperation: Salutary Diversions from de «Aid-effectiveness » Trail?", Development Policy Review, 32 (2), 179-202.

CAD (2014a). "Development Finance. Modernising Official Development Assistance (ODA). Options for Modernising ODA Measure", DCD/DAC(2014)3.

CAD (2014b). "Modernising the DAC's Development Statistics”, DCD/DAC(2014)9.

CAD (2014c). "Preparations for the High Level Meeting of the Global Partnership for Effective Development Co-operation", DCD/DAC(2014)10.

CEPEI (2014). "Una historia de dos alianzas. Tensiones y complementariedades de dos procesos globales de desarrollo", 10 años Cepei.

CHEN, S. y RAVALLION, M. (2012). "More Relatively-Poor People in a Less AbsolutelyPoor World", Policy Research Working Paper, 6114, The World Bank, julio.

COOPER, A. y FAROQ, A.B. (2013). "BRICS and the Privilegin of Informality in Global Governance", Global Policy, 4 (4), pp. 428-433. 
CORNIA, A. y MARTONARO, B. (2013). "Development policies and income inequality in selected developing regions, 1980-2010", Working Paper, 13, DISEI, Università degli Studi di Firenze.

DOLLAR, D. et al. (2013). "Growth Still is Good for the Poor", Policy Research Working Paper, 6568, The World Bank.

DOMíNGUEZ, R. (2011). "La crisis de identidad del sistema de ayuda", en Fundación Carolina, Nombres Propios, http://www.fundacioncarolina.es/esES/nombrespropios/ Paginas/nombrespropios.aspx [Último acceso abril de 2014].

DOMíNGUEZ, R (2013a). Más allá de la ayuda: una nueva métrica de la AOD post2015", Íconos. Revista de Ciencias Sociales, 47, pp. 31-45.

DOMÍNGUEZ, R (2013b). "Desmitificando la cooperación Sur-Sur", Centro de Pensamiento Estratégico Internacional https://www.academia.edu/3264989/Desmitificando_la_cooperacion_Sur-Sur_CEPEI_2013 [Último acceso abril de 2014].

EDWARD, P. y SUMNER, A. (2013). "The Geography of Inequality: Where and How Much Has Income Distribution Changed since 1990?", Center for Global Development Working Paper, 341, septiembre.

EMMERIJ, L. (2014). "The Future of Development Cooperation in Times of Crisis", Development and Change, 45(2), pp. 384-394.

EVANS, A. (2013). "Delivering the Post-2015 Development Agenda. Options for a New Global Partnership", Policy Brief, New York University Center on International Cooperation, noviembre.

EVANS, A. (2014). "Quadruple or Quits. Managing the overlaps between the 2015 on climate, trade, SDGs, and finance for development", Presentation to HGM $x$-Whitehall meeting, New York University Center on International Cooperation, febrero.

EVANS, A. y STEVEN, D. (2013a). "What happens now. The post-2015 agenda after the High-level Panel", Policy Brief, New York University Center on International Cooperation, junio.

EVANS, A. y STEVEN, D. (2013b). "What happens now. Taking the Post-2015 Agenda to the Next Stage", Policy Brief, New York University Center on International Cooperation, octubre.

FMI (2014). "Fiscal policy and income inequality", IMF Policy Paper, enero.

FUCHS, A. y VADLAMANNATI, K.C. (2013). "The Needy Donor. An Empirical Analysis of India's Aid Motives", World Development, 44, pp. 110-128.

G-20 (2011). 2011 Report of the Development Working Group, http://reliefweb.int/node/ 457485 [Último acceso abril 2014].

GANPE (2013). Una nueva alianza mundial: erradicar la pobreza y transformar las economías a través del desarrollo sostenible. Informe del Grupo de Alto Nivel de Personas Eminentes sobre la Agenda de Desarrollo Post-2015. New York: Naciones Unidas, mayo.

GLENNIE, J. (2014). "Will competing UN and OECD partnerships stymie effectiveness?", The Guardian Poverty Matters Blog, http://www.theguardian.com/global-development/poverty-matters/2014/apr/11/un-oecd-partnerships-aid-effectiveness?CMP=EMCGBLEML1625

GREVI, G. (2009). "The interpolar world: a new scenario”, Occassional Paper, 79, European Union Institute for Security Studies, junio. 
HYNES, W. y SCOTT, S. (2013). "The Evolution of Official Development Assistance: Achivementes, Criticisms and a Way Forward", IIIS Discussion Paper, 437, Insitute of International Integration Studies, octubre.

JANUS, H. et al. (2014). "How to Shape Development Cooperation? The Global Partnership and the Development Cooperation Forum", Briefing Paper, 3/2014, German Development Institute.

JIANG, Y. y FUES, T. (2014). "A Strong Voice for Global Sustainable Development: How China can Play a Leading Role in the Post-2015 Agenda", Briefing Paper, 2/2014, German Development Institute.

KANBUR, R. y SUMNER, A. (2012). "Poor Countries or Poor People? Development Assistance and the New Geography of Global Poverty", Journal of International Development, 24 (4), pp. 686-695.

KHARAS, H. y ROGERSON, A. (2012). Horizon 2025. Creative Destruction in the aid industry. Overseas Development Institute, s.l.

KIM, E.M. y LEE, J.E. (2013). "Busan and Beyond: South Korea and the Transition from Aid Effectivenes to Development Effectivenes", Journal of International Development, 25 (6), pp. 787-801.

KINDORNAY, S. y SAMY, Y. (2012). "Establishing a Legitimate Development Co-operation Architecture in the Post-Busan Era", The North-South Institute Working Paper, mayo.

LARRÚ, J.M. (2013). "La pobreza y las desigualdades en la agenda de desarrollo post2015", en J.A. Alonso dir., Compromiso global por un desarrollo incluyente y sostenible. Consideraciones sobre la agenda post-2015. Documentos de Trabajo Cooperación Española, 02/2013, AECID, diciembre pp.58-74.

LIN, J.Y. y WANG, Y. (2014). "China-Africa co-operation in structural transformation: Ideas, opportunities, and finances", WIDER Working Paper, 2014/046, UNU-WIDER, febrero.

MAXWELL, S. (2014). "«The Donors Dilemma». What is the future of International Development?", Global Policy Journal, 6 de enero, http://www.globalpolicyjournal.com/ blog/06/01/2014/donors\%E2\%80\%99-dilemma-what-future-international-development [Último acceso abril 2014].

MELAMED, C. (2014). "Inequality in post-2015: focus on targets, not the goals?", ODI Report, enero.

MIELNICZUK, F. (2013). "BRICS in the Contemporary World: changing identities, converging interests", Third World Quarterly, 34 (6), pp. 1075-1090.

MILANOVIC, B. (2012). "Global Income Inequality by the Numbers: in History and Now. An Overview", Policy Research Working Paper, 6259, The World Bank, noviembre.

MOLINA, E. et al. (2013). "Outcomes, Opportunity and Development. Why Unequal Opportunieties and Not Outcomes Hinder Economic Development", Policy Research Working Paper, 6735, The World Bank, diciembre.

MORAZÁN, P. et al. (2014). Modernising ODA in the framework of the post-MDG agenda: challenges and opportunities. Bruselas: Directorate-General for External Policies of the Union Policy Department.

MORRISON, W.M. (2014). "China's Economic Rise: History, Trends, Challenges, and Implications for the United States", Congressional Research Service Report, 7-5700, febrero 
NIELSEN, L. (2011). "Classifications of Countries Based on Their Level of Development: How it is Done and How it Could be Done", IMF Working Paper, 11/31, febrero.

NORTON, A. (2012). "The challenge of, and opportunities for, inclusive and sustainable development", DANIDA/ODI Working Paper, septiembre.

OCDE (2010a). Perspectives on Global Development 2010. Shifting Wealth. París: OECD Development Centre.

OECD (2010b): Inside the DAC. A Guide to the OECD Development Assistance Committee. París: OECD.

OECD (2011). Perspectives on Global Development 2012. Social Cohesion in a Shifting World. París: OECD Development Centre.

OECD (2012). "Looking to 2060: Long-term global growth prospects. A going for growht report", OECD Economic Policy Papers, 03.

OECD (2013a). The People's Republic of China. Avoiding the Middle-Income Trap: Policies for Sustained and Inclusive Growth. París: OECD.

OECD (2013b). "Effective development co-operation: an important enabler in a post2105 global development framework", Paper, 1, OECD and post-2015 reflections.

BURGES, S. (2014). "Brazil's International Development Co-operation: Old and New Motivations", Development Policy Review, 32 (3), pp. 355-374.

OLINTO, P. et al. (2013). "The State of the Poor: Where Are The Poor, Where Is Extreme Poverty Harder to End, and What Is the Current Profile of the World's Poor?", Economic Premise, 125, The World Bank.

OLIVIÉ, I. e I. MOLINA (2011). "Índice Elcano de Presencia Global”, Estudios Elcano 2, Real Instituto Elcano.

OLIVIÉ, I. coord. (2011). Nunca desaproveches una buena crisis. Hacia una política pública española de desarrollo. Informe Elcano, 13.

OLIVIÉ, I. y DOMíNGUEZ, R. (2013). Elementos para el posicionamiento de España en la construcción de la agenda de desarrollo global. Informe Elcano, 14.

OLIVIÉ, I., M. GRACIA y C. GARCÍA-CALVO (2014). Informe Elcano de Presencia Global 2014, Real Instituto Elcano.

RAVALLION, M. (2005). "Inequality is Bad for the Poor", Policy Research Working Paper, 3677, The World Bank, agosto.

RAVALLION, M. (2012). "Benchmarking Global Poverty Reduction", Policy Research Working Paper, 6205, The World Bank, septiembre.

RINKE, B. y SCHENECKENER, U. (2012). "Informalisation of World Politics? Global Governance by Clubs", en T. Debiel et al. (eds.), Global Trends 2013. Peace, Development, Enviroment. Bonn/Duissburg: Development and Peace Foundation / Institute for Development and Peace, pp. 21-35.

ROSENBLAT, D. y MCGAVOCK, T.J. (2013). "A Note of the Simple Algebra of the Shared Prosperity Indicator", Policy Research Working Paper, 6645, The World Bank.

SACHS, J. dir. (2013). Una agenda de acción para el desarrollo sostenible. Informe para el Secretario General de las Naciones Unidas. Consejo de Liderazgo de la Red de Soluciones para el Desarrollo Sostenible, octubre

SGNNUU (2013). Una vida digna para todos: acelerar el logro de los Objetivos de Desarrollo del Milenio y promover la agenda de las Naciones Unidas para el Desarrollo, Informe del Secretario General, A/68/202, 26 de julio de 2013. 
SOULÉ-KHONDOU, F. (2014). "South Africa competing with other BRICS in Africa", GREAT insights, 3 (4), pp. 39-41.

SUMNER, A. (2012a). "Where Do The Poor Live?", World Development, 40 (5), pp. 865877.

SUMNER, A. (2012b). "Where Will the World's Poor Live? An Update of Global Poverty and the New Bottom Billion", Center for Global Development Working Paper, 305, septiembre.

SUMNER, A. (2012c). "Beyond the MDGs. The post-2015 development agenda: What is the global poverty "problem», how is it changing and what does that mean for any new MDGs?, en R. Domínguez y S. Tezanos, Desafíos de los Estudios del Desarrollo. Actas del I Congreso Internacional de Estudios del Desarrollo. Santander: Red Española de Estudios del Desarrollo, pp. 98-145.

SUMNER, A. (2012d). "The Buoyant Billions: How «Middle Class» Are the New Middle Classes in Developing Countries? (And Why Does It Matter?)", Center for Global Development Working Paper, 305, septiembre.

TRAN, M. (2013). "Apathy over aid effectiveness threatens global partnership", The Guardian Poverty Matters Blog, http://www.theguardian.com/global-development/poverty-matters/2013/aug/15/apathy-over-busan-aid-effectiveness [Último acceso abril 2014].

WEF (2014). Global Risks 2014. Geneva: World Economic Forum. 